DOI: $10.5604 / 01.3001 .0013 .2549$

\title{
INFORMATION TECHNOLOGIES FOR THE ANALYSIS OF THE STRUCTURAL CHANGES IN THE PROCESS OF IDIOPATHIC MACULAR RUPTURE DIAGNOSTICS
}

\author{
Sergii Pavlov ${ }^{1}$, Yosyp Saldan², Dina Vovkotrub-Lyahovska², Yuliia Saldan², Valentina Vassilenko ${ }^{3}$, \\ Yuliia Yakusheva ${ }^{2}$ \\ ${ }^{1}$ Vinnitsa National Technical University, ${ }^{2}$ Vinnitsa Pirogov National Medical University, ${ }^{3}$ Universidade Nova de Lisboa, Faculdade de Ciências e Tecnologia
}

Abstract. Process of eye tomogram obtaining by means of optical coherent tomography is studied.Stages of idiopathic macula holes formation in the process of eye grounds diagnostics are considered. Main stages of retina pathology progression are determined: Fuzzy logic units for obtaining reliable conclusions regarding the result of diagnosis are developed. By the results of theoretical and practical research system and technique of retinal macular region of the eye state analysis

Keywords: tomogram, optical coherent tomography, macular area, fuzzy logic, membership function, idiopathic macular break.

\section{TECHNOLOGIE INFORMACYJNE W CELU ANALIZY ZMIAN STRUKTURALNYCH W PROCESIE DIAGNOSTYKI IDIOPATYCZNYCH OTWORÓW PLAMKI}

Streszczenie. W artykule omówiono proces uzyskiwania tomogramu oka za pomoca optycznej tomografii koherentnej. Rozważane sa etapy powstawania idiopatycznych plamek żóltych $w$ procesie diagnostyki podstawy oka. Określono główne etapy progresji patologii siatkówki: opracowanie modeli logiki rozmytej, w celu uzyskania wiarygodnych wniosków dotyczacych wyniku diagnozy. Na podstawie wyników badań teoretycznych i rezultatów uzyskanych z układu badawczego i techniki regionu plamki żóltej przeprowadzono analizy stanu oka.

Słowa kluczowe: tomogram, optyczna tomografia koherentna, obszar plamki, logika rozmyta, funkcja przynależności, idiopatyczna przerwa plamkowa

\section{Introduction}

Nowadays the enlargement of knowledge concerning the development of the pathologic changes in human organism occurs, that is why, there appears the necessity to create modern information devices and methods of the processing of biomedical information, in particular, images. It is known that while making a diagnosis and carrying out treatment doctors often use biomedical images, obtained by means of various hardware - software complexes. In particular, in the field of the ophthalmology these complexes include optic coherent tomography, Heidelberg Retinal Tomography, Laser-based Retinal Polarimetry, Rectal Thickness Scanner analyzer, etc.

The most widely used are 1D, 2D and 3D images of the eye, including the fundus of eye; interpretation of these images takes a lot of efforts and much time. The diagnostician has to adjust his manner of thinking to obtain the aggregate picture, avoid the mistakes and make a correct diagnosis. That is why, very often there appears the need in using the algorithms of the analysis and processing of biomedical images which will help the staff to cope with large volume of data, providing the reliable support in diagnostics and treatment.

\section{Aim and tasks of the research}

The aim of the research is the enhancement of the reliability of the biomedical data analysis, developing the method of the processing the tomograms of the eye retina, the method is used in the system of the diagnostics of idiopathic macular ruptures (IMR).

\section{Methods of the fundus of the eye visualization and processing of results obtainer}

The authors made the assessment of the characteristics of various types of the equipment, in particular, their technical data, characteristic features, advantages and disadvantages. Such diagnostic devices were considered:

1) HPT - Heidelberg Retina Tomography, Heidelberg Engineering, Heidelberg, Germany;

2) GDx x VCC - Glaucoma Diagnostics Variable Cornea
Compensation, till 2004 it was manufactured by the company Laser Diagnostics Technologies, San Diego, USA, after 2004 by the company Carl Zeiss Meditec, Dublin, USA;

3) OCT - Optical Coherence Tomograph, Carl Zeiss Meditec, Dublin, USA:

4) RTA - Retinal Thickness Analyzer, Talia Technology, Neve Ilan, Israel.

Image obtaining is performed applying non-invasive method, quickly, at a low level of lighting that enables to use the technology in every-day clinical practice. The accuracy of CSLO is based on the optic law of the confocality, when the beam, reflected from the preset plane, by-passes the diaphragm, located in front of the detector and is taken into account by the device and the beam, reflected from the plane, located outside the investigated zone - is absorbed by the diaphragm.

For obtaining the images of HRT the diode laser is used (wave length $-670 \mathrm{~nm}$ ). In HPT the system of automatic control of measurements quality is built-in, the system reveals and reshapes the scanned images of a poor quality, which are connected with possible winking or the change of gaze fixation of the patient. This enables to obtain for the analysis three series of scans. In order to create the necessary topographic image the program automatically centers and averages the scanned images for each series of the scanning.

At the same time the given method has some limitations: the necessity to plot the contour line by the operator; dependence of the greater part of the studied parameters on the basis plane; dependence of the image quality on the level of the ocular pressure; complexity of the research in case of artifacts and astigmatism of high degree; very high variability of the normative base of the healthy men creates problems in the diagnostic search during the first investigation.

Laser polarimetry, which is the base of GDx devices, was suggested for the determination of the thickness of the retinal nerve fibers layer $[8,9,22]$. Its principle is that in the middle of the eye, across the pupil, the laser beam with the polarized light is directed. The beam meets on its way the structural hindrance, for instance, the layer of axons, and is divided into two beams, located perpendicular to each other. Velocity of the beams across the axons is not the same due to the braking effect, which, in its turn, depends on the thickness of the axons layer. 
By means of the software the device measures the thickness of the given structure, separating power of which is rather high [6]. The accuracy of polarimetric studies suffered for a long time due to the impossibility to compensate birefringence $[3,4,7]$. More wide spreading the technique obtained after the developers managed to neutralize the action of such optical structures of the eye, as the eye cornea and crystal, which have the ability to birefringence, that in its turn, gave the error in the process of measurements [5, 23]. Fig. 1 shows the results of GDx device scanning with the compensator of the birefringence and without it.

Optic Coherence Tomography (OCT) - is the method of diagnostics, which enables to obtain in vivo $2 \mathrm{D}$ transverse images of the retina, optic disk and the structures of the front part of the eye. The method was introduced into the clinical practice in 1991 and is based on the principles of Michelson interferometry.

Low-coherent light beam passing through the retina tissue is reflected by the structures, located in its layers and the degree of the reflection depends on the density and thickness of the layers as well as on the preset distance, at which the studied structure is located from the source of light. Another, reflecting beam, allows with high separation power to record and diagnose the smallest structural changes $[1,11,12]$.
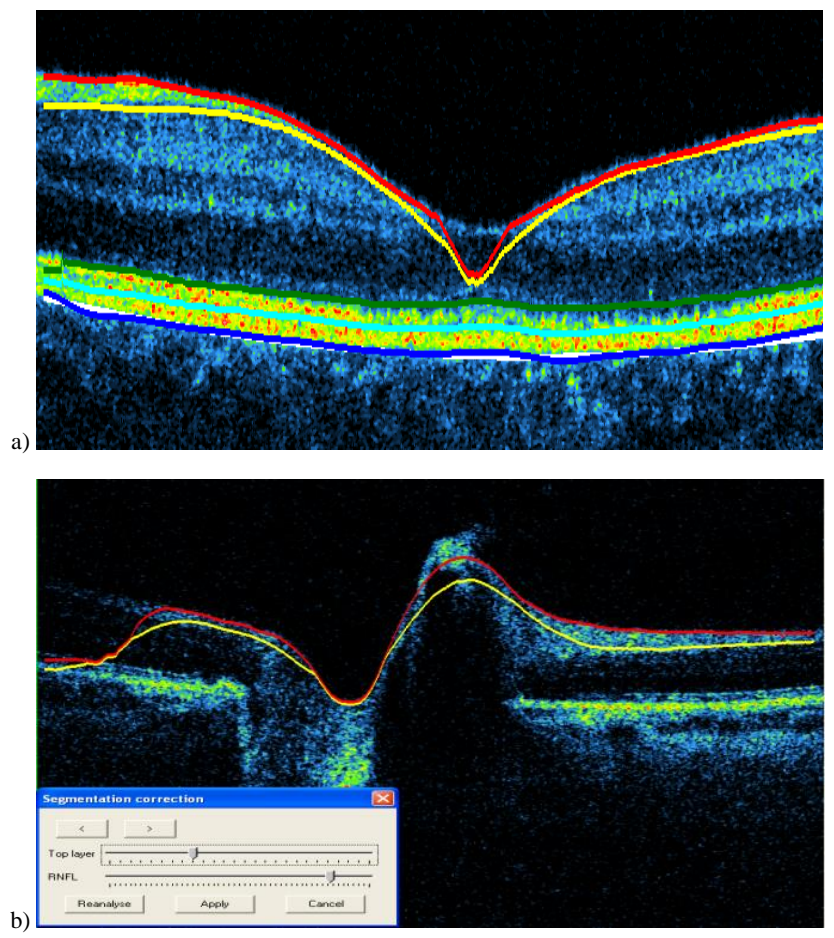

Fig. 1. Tomograms of the macular eye region with the allocated contours by the standard procedure: a) normal retina tomogram of the macular region, b) tomogram of the optic nerve

Studies, performed at Retinal Thickness Analyzes (RTA), are based on scanning of the retina surface and formation of its topographic map by means of HeNe laser with the wavelength of $543 \mathrm{~nm}$. The laser beam layer-wise passes through the retina, deliminating and fixing peaks between vitreoretinal and chorioretinal surfaces, determining the output thickness of the retina. Total scanning depth of the device - up to $3 \mathrm{~mm}$ (16 optic partitions, one partition $-0.1875 \mathrm{~mm}$ ). Taking into account high measurement error in the process of using the given method (up to $20 \%$ ) it did not find wide application both in Ukraine and abroad [16].

The limitations of the method are the following: the need of the basis plane for certain topographic parameters; need of the mydriasis for the macular scanning; lack of quality autocontrol; very high variability of the normative base of the healthy men creates problems during the first investigation; high error of the reproducibility (up to 20\%); changed crystal (cataract) absorbs the green colour of the laser and worsens the quality of the research in $50 \%$ of cases; the need of additional mydriasis.

\section{Realization of the method of the eye retina macular region tomograms processing}

OCT is used for the treatment of all the diseases of the central region of the retina and has some advantages: possibility of the application in any age; determination of the exact layer-wise structure of the retina; accurate visualization of the retina changes in case of various pathologies; determines the smallest structural changes at any stage of the process; the method is irreplaceable for the intermediate (dynamic) observation and assessment of the retina diseases treatment efficiency [7]

Tomograms are presented in the real-time by means of the color scale that shows the amount of light, dissipated by the tissues at different depth. Fig. 2 shows the image of the normal tomogram of the retina.

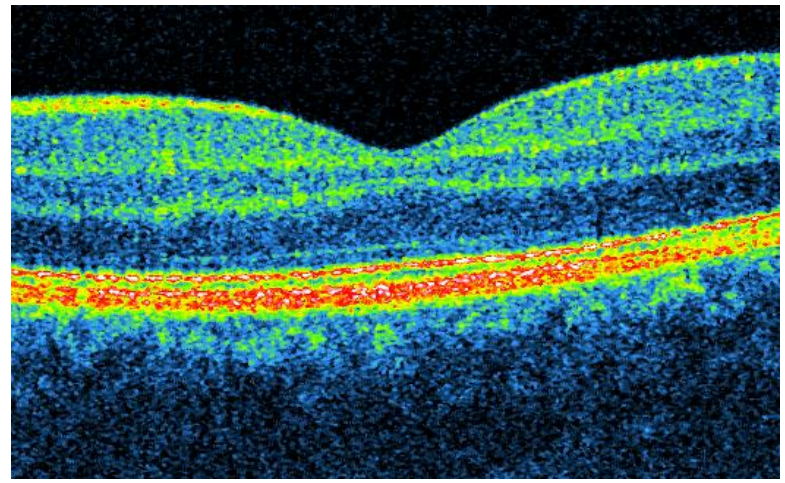

Fig. 2. Initial image of the retina of the macular region without processing

For the determination of the retina thickness, nerve fiber layer, various parameters of the macular the standard procedure is used, it includes the allocation of the zones in the tomogram, as a result, the needed calculations can be performed. Standard procedure, carried out after obtaining the eye tomogram, allocates tones only with $70 \%$ validity.

As it is seen from Fig. 1a, there arises the problem of the distinct allocation of the boundaries on the tomogram, that would give the possibility to improve not only the determination of the retina layers of the macular region, but as a result perform more reliable eye diagnostics. To realize the unit of the preliminary processing of the tomograms, allocate the contour, in particular, fovea macular zone, a number of the transformations of the given image was performed.

Preliminary results of the analysis of the cell structures in the process of the histological examinations allows to make a conclusion that the greater part of the images in the process of their formation (photographing, scanning, etc.) fall under the impact of a number of negative factors, this leads to the appearance of the low-contrast and noisy sections [9].

For the beginning the author selected the retina tomogram of the macular region of the healthy patient. (Fig. 2a).

That is why it is expedient to apply the process of image cleaning from noise during the preprocessing of the image $[6,22]$

To carry out this procedure the smoothing $2 \mathrm{D}$ median filter was chosen, the result of its application is shown in Fig. 3.

The window of the median filter gradually slides on the image and at each step turns one of the elements, which fell into the aperture of the filter. The given filtration realizes the change of counting's values in the centre of the aperture. The output signal $y_{m}$ of the median filter of $2 n+1$ of width for the current counting of $\mathrm{m}$ is formed from 12 input time series ..., $x_{m-1}, x_{m}, x_{m+1}, \ldots$ :

$$
y_{m}=\operatorname{med}\left(x_{m-n}, x_{m-n+1}, \ldots, x_{m-1}, x_{m}, x_{m+1}, \ldots, x_{m+n-1}, x_{m+n}\right),
$$

where $\operatorname{med}\left(x_{1}, \ldots, x_{k}, \ldots, x_{2 n+1}\right)=x_{n+1}, x_{k}-$ elements of the variational series, $x_{k}$ : 


$$
\begin{gathered}
x_{1}=\min \left(x_{1}, x_{2}, \ldots, x_{2 n+1}\right) \leq x_{(2)} \leq x_{(3)} \leq \ldots \leq x_{2 n+1} \\
=\max \left(x_{1}, x_{2}, \ldots, x_{2 n+1}\right) .
\end{gathered}
$$
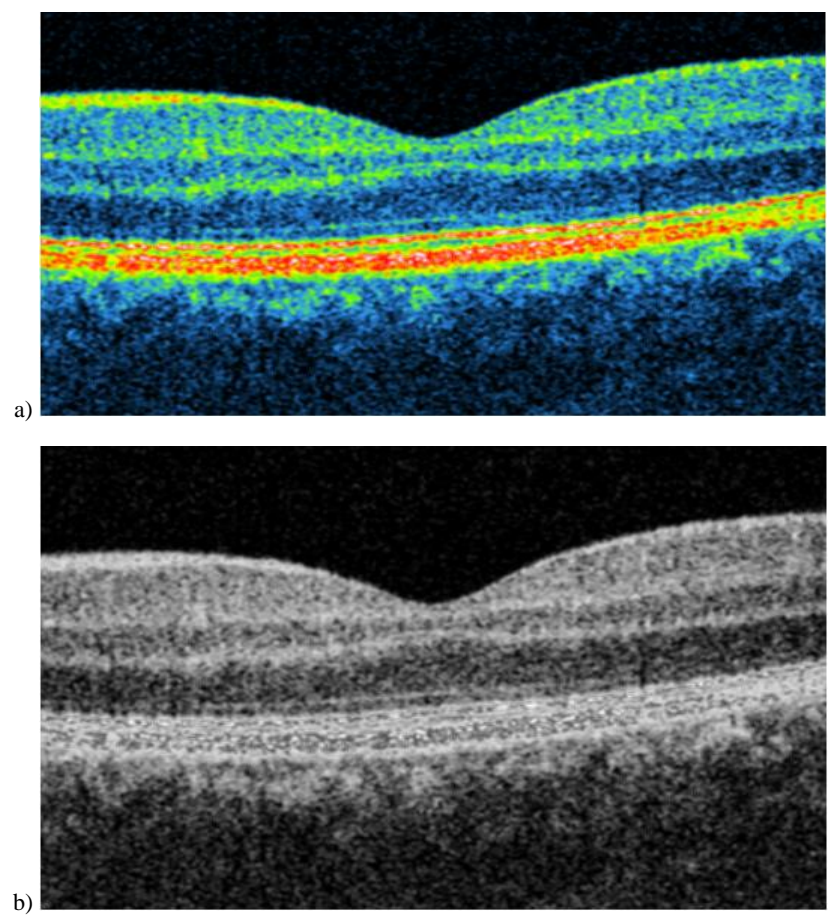

Fig. 3. a) Image after the application of the smoothing $2 D$ median filter, $b$ ) image of the retina of the macular zone after the transformation in black and white format

Since the image is information oversaturated to perform the next steps, namely, colors inversion, it is better to turn the image into black and white one (Fig. 3b).

Conversion of the color image into grayscale is carried out by means of the multiplication of three colors of each pixel on the image and obtaining the number of the grayscale by the formula 2 .

$$
\begin{aligned}
& F(x, y)=0.2989 \cdot f(x, y) \cdot R+0.587 \\
& \cdot f(x, y) \cdot G+0.114 \cdot f(x, y) . B
\end{aligned}
$$

$f(x, y) \cdot R$ - value of the color number of the red scale;

$f(x, y) . G$ - value of the color number of the green scale;

$f(x, y) . B$ - value of the color number of the blue scale.

Each obtained number of the gray shade is written into a new matrix at the same place of the matrix coordinates that in the matrix of the color image. [6].

Thus, a new image in gray scale was obtained from the color image of the tomogram of the retina of the macular zone (Fig. 3b)

For obtaining well defined contours of the macular region, the given tomogram is necessary to invert, this will give us the possibility to deliminate the boundaries better (Fig. 4). The process of colors inversion is the search through of each pixel and assigning it the reversed color and, as we have black and white image, then this process is simplified in order to assign the black color to the white with the corresponding coefficient, and black to the white with the corresponding coefficient.

Binarization of the images was carried out for the conversion of the images in gray gradations into monochromatic, i.e. the image where only two types of pixels are available (dark and light). Image binarization is performed applying Bernsen method, also known as the threshold binarization.

This contrast threshold is a constant for the white image but for each input image it is selected on the base of the histogram analysis.

The following steps are made in the process of image binarization: the input image with the allocated contour is obtained; histogram is made and analyzed and the value of the threshold is obtained; each pixel of the image is verified, if in the given coordinate the value is less than the threshold value, «1» is written, otherwise « $0 »$ is written; binary image is obtained (Fig. 4b).
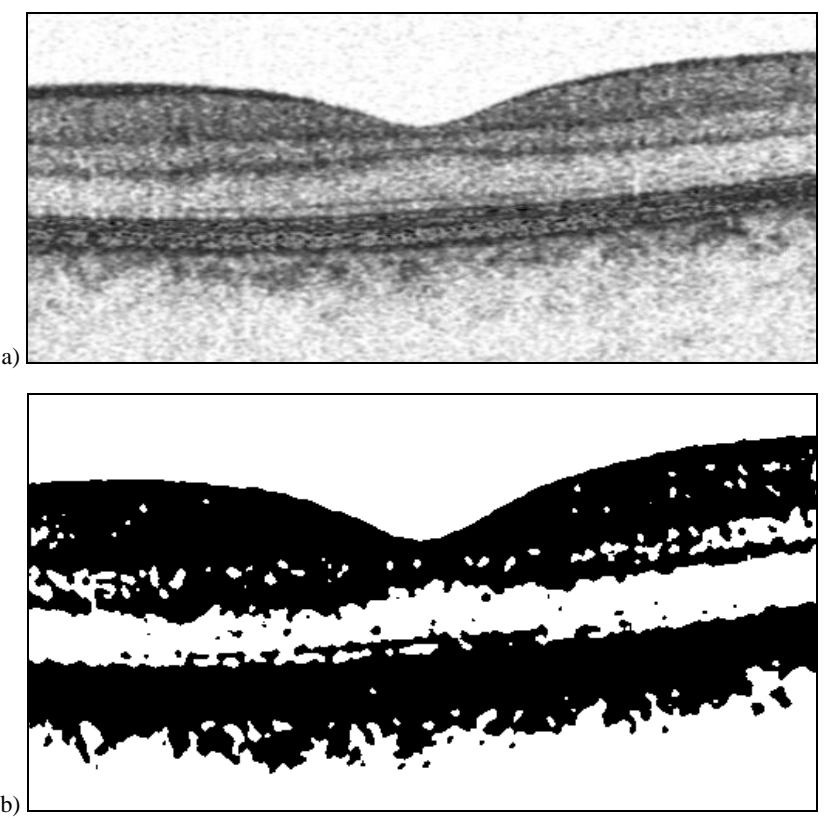

Fig. 4. Image of the retina of macular zone a) Image of the retina of macular zone after the inversion is performed; b) Image of the retina of macular zone after the binarization

Also the optimal value of the threshold can be obtained after the determination of the maximum value of the amplitude of the gray $g_{\max }$ and minimum value $g_{\min }$, after that average number of pixels which entered the range from the minimal value to the average is calculated:

$$
T_{\text {opt }}=\left(g_{\max }-g_{\text {min }}\right) \sum_{g=g_{\min }}^{g \text { mid }} p(g)
$$

where $T_{\text {opt }}$ - optimal threshold; $g_{\max }, g_{\min }, g_{\text {mid }}$ - maximum, minimum and average value of the amplitude of the gray; $p(g)-$ set of the gray.

As it is seen from Fig. 5 visually it is possible to recognize the boundaries but for more accurate results it is necessary to use Sobel filter (Fig. 5a). As the contour is the contrast region of the image, that contains sharp difference of the brightness between two neibouring pixels, then such drops of the brightness as a rule, are the boundaries of the object, where background and brightness of the object itself differ greatly. Algorithm of boundaries determination establishes both horizontal and vertical boundaries (Fig. 5a).

For Sobel filter the window is used:

$$
M_{\text {Sobel }}=\left|\begin{array}{ccc}
f_{i-1, j-1} & f_{i-1, j} & f_{i-1, j+1} \\
f_{i, j-1} & f_{i, j} & g_{i, j+1} \\
f_{i+1, j-1} & f_{i+1, j} & g_{i+1, j+1}
\end{array}\right|
$$

where $(i, j)^{\text {th }}-$ pixel is attributed the value of the brighness instead of $f(i, j)$

$$
g_{i, j}=\left(X^{2}+Y^{2}\right)^{\frac{1}{2}}
$$

$$
\begin{gathered}
g_{i, j}=|X|+|Y|, \\
X=\left(f_{(i-1),(j-1)}+2 f_{(i-1) j}+f_{(i-1),(j+1)}\right)- \\
\left(f_{(i+1),(j-1)}+2 f_{(i+1) j}+f_{(i+1),(j+1)}\right), \\
Y=\left(f_{(i-1),(j-1)}+2 f_{i,(j-1)}+f_{(i+1),(j-1)}\right)- \\
\left(f_{(i-1),(j+1)}+2 f_{i,(j+1)}+f_{(i+1),(j+1)}\right)
\end{gathered}
$$

Unlike the smoothing filters and filters that increase the contrast rate, which do not change average intensity of the image, 
as a results of using difference operators the images with the average value of the pixel close to zero are obtained. Pixels with large by modulus values on the finite image correspond to the vertical boundaries of the output image.

That is why difference filters are also called filters that find the boundaries. As it is seen from Fig. 5a Sobel filter allocated the contours, we invert the colors for obtaining distinct lines (Fig. 5b) that can be plotted as a mask on the initial biomedical image.

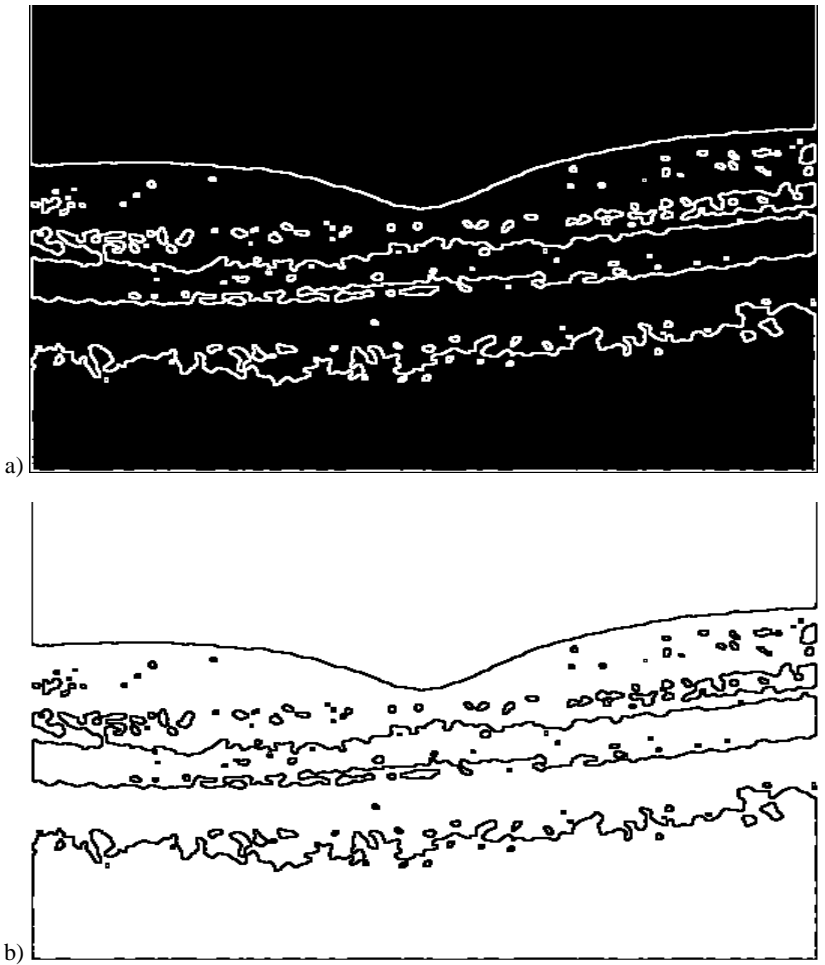

Fig . 5. a) Image of the retina of the macular zone after using Sobel filter, b) image of the retina of the macular zone after the inversion is performed

\section{Practical realization}

Fig. 6 shows what form has the obtained image with the plotted mask, the red color shows the upper boundary. The condition for carrying out the research was the development of the technology for the processing of the tomogram of the macular region retina, that would give the possibility to improve the accuracy of the macular region contour determination to the value of $98 \%$.

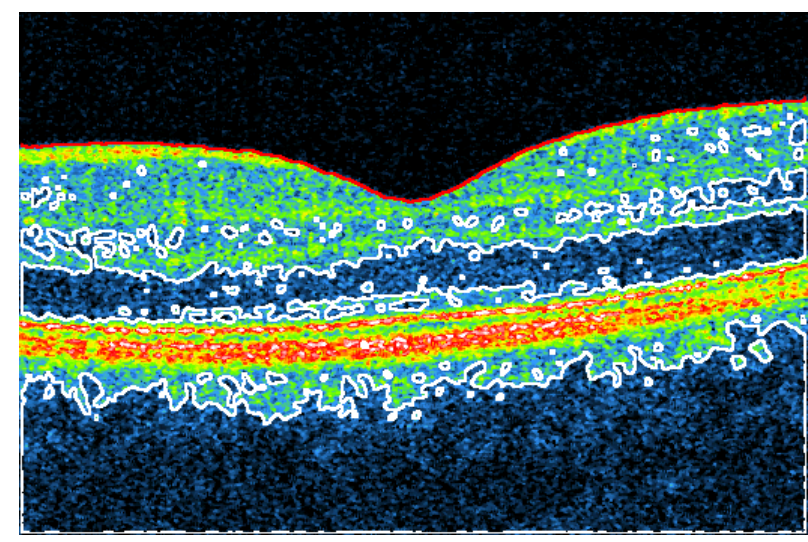

Fig. 6. Initial image of the retina of the macular zone with the applied mask

The author developed the technology of such images processing which allocates the macular region with high accuracy. Visually this can be demonstrated comparing the images, which were processed by the standard procedure and by our technology (Fig. 7, 8) [3, 4, 7].
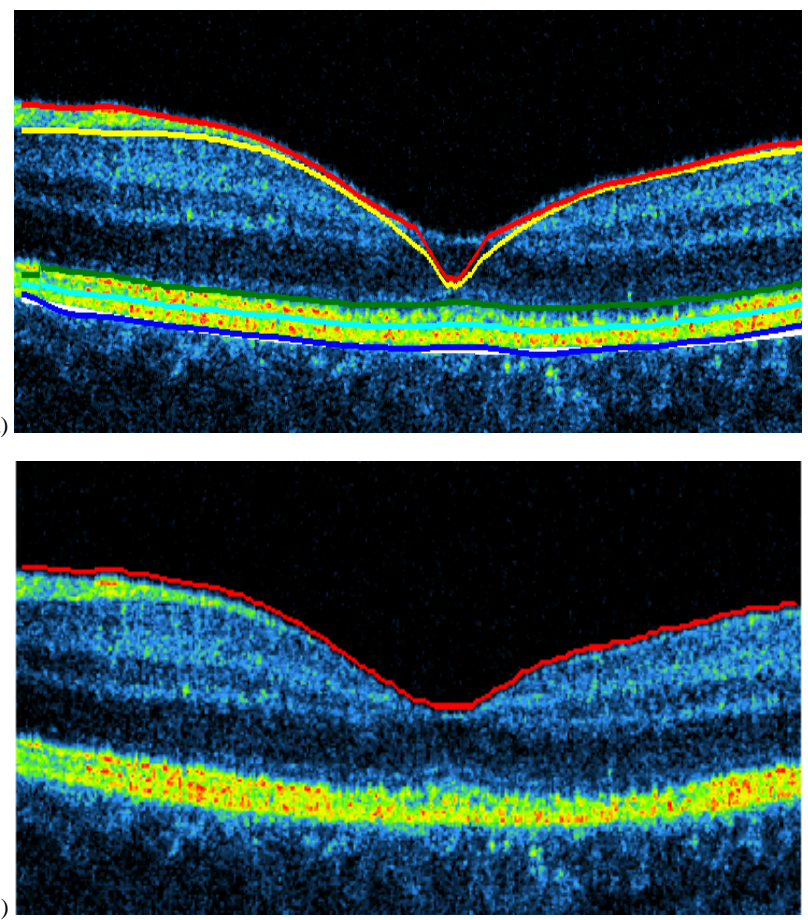

Fig. 7. a) Normal tomogram of the macular zone retina; a) standard technology, b) suggested technology

Procceding from the above-mentioned we can state that having applied the developed method of processing for the tomograms of the macular zone retina, better efficiency of the contrours allocation is achieved. In its turn, this improves the accuracy of the macular region parameters determination.
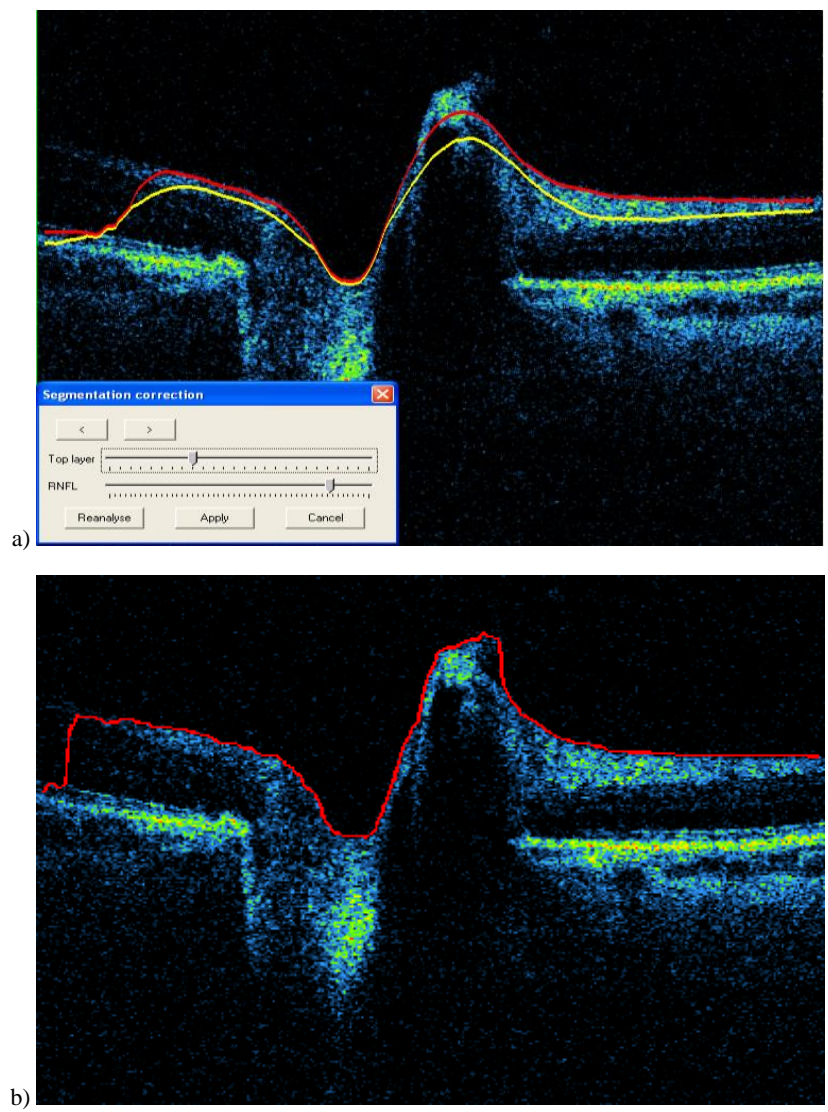

Fig. 8. Tomogram of the optic nerve disk using a) standard technology, b) suggested technology 
Realization of the information input and processing unit of the biomedical expert system is presented in Fig. 9, where 1 - open the file; 2 - close the file; 3 - save the file; 4 - initial image; 5 chromatity (represent the values of $\mathrm{R}, \mathrm{G}, \mathrm{B}$ ); 6 - contour allocation; 7 - graphs plotting; 8 - improvement of the image parameters; 9 - full screen mode; 10 - help; 11 - image analysis; 12 - button; 13 - histograms by R, G, B; 14 - language.

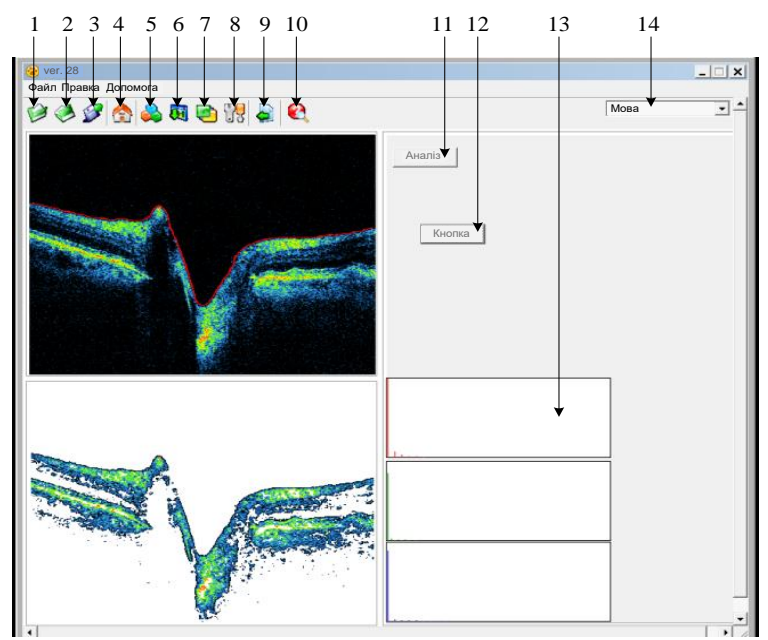

Fig. 9. Program for the processing of the tomogram of retina of the macular region of the eye

It was established practically that image processing by means of masks in the space range is more efficient that the realization of the similar actions in the frequency range because less time is needed for carrying out the processing.

The rate of the frequency filtration does not depend on the size of the mask, performing of convolution of the image with the mask of the super large dimensions (approximately $120 \times 120$ elements and more) is expedient to carry in the frequency range.

\section{Conclusions}

The given research further develops the mathematical models for the analysis of the biomedical images of the macular area of the retina using the methods of fuzzy sets on the base of the experimental knowledge bases that allowed to carry out complex qualitative diagnostics and improve its reliability by $22 \%$ as well as the developed method of processing the fundus of eye, which, unlike the existing one, has the possibility to create the sliceable mask, that enables to determine more exactly the contours of the macular region of the eye retina.

The expediency of application the methods of image brightness correction, in case of its general blurring and the technique of the sliceable masking for the improvement of the image definition was proved practically. Better quality of the periodic noise elimination by the median filtration as compared with adaptive Wiener filtering is established. Minor advantage in speed of realization the adaptive Wiener filtering over the median filtration in MATLAB package is practically determined, that is why the given peculiarity must be taken into account when creating new methods of the space processing of the images, which will use the above mentioned filters.

\section{References}

[1] Alamouti B., Funk J.: Retinal thickness decreases with age: an OCT study. Br. J. Ophthalmol. 87/2003, 899.

[2] Alamouti B., Funk J.: Retinal thickness decreases with age: an OCT study. Br. J. Ophthalmol. 87/2003, 899.

[3] Bagga H., Greenfield D.S., Knighton R.W.: Scanning laser polarimetry with variable corneal compensation: identification and correction for corneal birefringence in eyes with macular disease. Invest. Ophthalmol. Vis. Sci. 44/2003, 1969-1976

[4] Bagga H., Greenfield D.S., Feuer W., Knighton R.W.: Scanning laser polarimetry with variable corneal compensation and optical coherence tomography in normal and glaucomatous eyes. Am. J. Ophthalmol. 135/2003, 521-529.

[5] Bowd C., Zangwill L.M., Weinreb R.N.: Association between scanning laser polarimetry measurements using variable corneal polarization compensation an visual field sensitivity in glaucomatous eyes. Arch. Ophthalmol. 121/2003, 961966

[6] Bowd C., Zangwill L.M., Medeiros F.A., et al.: Confocal scanning laser ophthalmoscopy classiliers and stereophotograph evaluation for prediction of visual field abnormalities in glaucoma-suspect eyes. Invest. Ophthalmol. Vis. Sci. 45/2004, 2255-2262.

[7] Greenfield D.S., Knighton R.W., Feuer W.J., Schiffman J.C.: Normative retardation data corrected lor the corneal polarization axis with scanning laser polarimetry. Ophthalmic. Surg. Lasers. Imaging. 34/2003, 165-171.

[8] Gurses-Ozden R., Hon H., Ishikawa S.TLiebmann., J.M.: Increasing sampling density improves reproducibility of optical coherence tomography measurements. J. Glaucoma 8/1999, 238-241.

[9] Jones A.L., Sheen N.J., North R.V., et al.: The Humphrey optical coherence tomography scanner: quantitative analysis and reproducibility study ol the normal human retinal nerve fibre layer. Br. J. Ophthalmol. 85/2001, 673.

[10] Pavlov S.V., et al.: Methods of processing biomedical image of retinal macular region of the eye, Proc. SPIE 9961, Reflection, Scattering, and Diffraction from Surfaces V, 99610X (September 26, 2016); [DOI:10.1117/12.2237154].

[11] Pavlov S.V., et al.: Tele-detection system for the automatic sensing of the state of the cardiovascular functions in situ. Information Technology in Medical Diagnostics II. CRC Press Balkema book, London 2019, 289-296.

[12] Pavlov S.V., Martianova T.A., Saldan Y.R., et al.: Methods and computer tools for identifying diabetes-induced fundus pathology. Information Technology in Medical Diagnostics II. CRC Press, Balkema book, London 2019, 87-99.

[13] Romanyuk O.N., et al.: Method of anti-aliasing with the use of the new pixel model, Proc. SPIE 9816, Optical Fibers and Their Applications 2015, 981617 (December 18, 2015), [DOI:10.1117/12.2229013].

[14] Romanyuk S.O.: New method to control color intensity for antialiasing. Control and Communications (SIBCON), 2015 International Siberian Conference. 21-23 May 2015. [DOI: 10.1109/SIBCON.2015.7147194].

[15] Saldan Y.R., et al.: Efficiency of optical-electronic systems: methods application for the analysis of structural changes in the process of eye grounds diagnosis. Proc. SPIE 10445, Photonics Applications in Astronomy, Communications, Industry, and High Energy Physics Experiments 2017, 104450S, [DOI: 10.1117/12.2280977].

[16] Sergey I., et al.: Offsetting and blending with perturbation functions. Proc. SPIE 11045, Optical Fibers and Their Applications 2018, 110450W, 2019 [DOI: $10.1117 / 12.2522353]$.

[17] Timchenko L.I., et al.: Bio-inspired approach to multistage image processing. Proc. SPIE 10445, Photonics Applications in Astronomy, Communications, Industry, and High Energy Physics Experiments 2017, 104453M, [DOI: $10.1117 / 12.2280976]$

[18] Timchenko L.I., et al.: Precision measurement of coordinates of power center of extended laser path images. Proc. SPIE 10808, Photonics Applications in Astronomy, Communications, Industry, and High-Energy Physics Experiments 2018, 1080810 [DOI: $10.1117 / 12.2501628$ ].

[19] Vyatkin S.I., et al.: Offsetting and blending with perturbation functions. Proc. SPIE 10808, Photonics Applications in Astronomy, Communications, Industry, and High-Energy Physics Experiments 2018, 108082Y, [DOI $10.1117 / 12.2501694]$.

[20] Vyatkin S.I., et al.: A GPU-based multi-volume rendering for medicine. Proc. SPIE 11045, Optical Fibers and Their Applications 2018, 1104513, 2019 [DOI 10.1117/12.2522408].

[21] Vyatkin S.I., et al.: Using lights in a volume-oriented rendering. Proc. SPIE 10445, Photonics Applications in Astronomy, Communications, Industry, and High Energy Physics Experiments 2017, 104450U, [DOI: 10.1117/12.2280982].

[22] Weinreb R.N., Bowd C., Greenfield D.S., Zangwill L.M.: Measurement of the magnitude and axis of corneal polarization with scanning laser polarimetry. Arch. Ophthalmol. 120/2002, 901-906.

[23] Zhou Q., Weinreb R.N.: Individualized compensation of anterior segment birefringence during scanning laser polarimetry. Invest. Ophthalmol. Vis. Sci. 43/2002, 2221-2228. 


\section{Prof. Sergii Pavlov}

e-mail:psv@vntu.edu.ua

Doctor of Technical Sciences, Professor, Academician of the International Academy of Applied Radioelectronic. Vice-rector of for Scientific Work of Vinnytsia National Technical University, professor of biomedical Engineering

Scientific direction - biomedical information optoelectronic and laser technologies for diagnostics and physiotherapy influence. Deals with issues of improving the distribution of optical radiation theory in biological objects, particularly through the use of electro-optical systems, and the development of intelligent biomedical optoelectronic diagnostic systems and standardized methods for reliably determining the main hemodynamic cardiovascular system of comprehensive into account scattering effects.

ORCID ID: 0000-0002-0051-5560

\section{Prof. Yosyp Saldan}

e-mail: ysaldan@ukr.net

Doctor of Medical Sciences, Professor of Eye Diseases and Eye Microsurgery Department, Pirogov National Medical University of Vinnytsia

Scientific direction - information technologies for the analysis of the structural changes in the process of idiopathic macular rupture diagnostics, development of biomedical technologies through the use of new technologies in the field of research of image processing, development of information-measuring systems diagnostic monitoring.

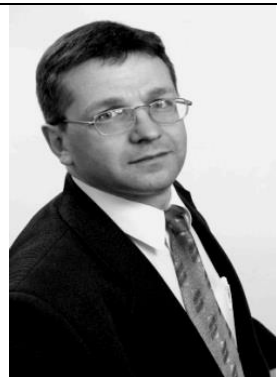

ORCID ID: 0000-0002-3925-9197

\section{Ph.D. Dina Vovkotrub-Lyahovska}

e-mail: vovkotrub@vntu.edu.ua

Senior lector of Vinnytsia National Technical University, researcher of Company "Sperko" Vinnytsia

The scientific direction of work is the creation of systems for the diagnosis of fundus abnormal pathologies, the technology of standardization of methods for biomedical information analysis, and the processing of biomedical images.

ORCID ID: 0000-0001-6793-5407
Ph.D. Yuliia Saldan

e-mail: ysaldan@ukr.net

Docent of Eye Diseases and Eye Microsurgery Department, Pirogov National Medical University of Vinnytsia.

Scientific direction - information technologies for the analysis of the structural changes in the process of idiopathic macular rupture diagnostics, development of biomedical technologies through the use of new technologies in the field of research of image processing, development of information-measuring systems diagnostic monitoring.

ORCID: 0000-0001-7420-598X

Prof. Valentina B. Vassilenko e-mail: vv@ fct.unl.pt

D.Sc., prof. Universidade Nova de Lisboa, Faculdade de Ciências e Tecnologia, 2829-516 Caparica, Portugal.

Development of biomedical technologies through the use of new technologies in the field of research of image processing, machine learning, deep learning, artificial intelligence, development of optoelectronic, microelectronic and nanotechnology in the creation of opto-electronic means, biomedical optics; development of information-measuring system diagnostic monitoring.

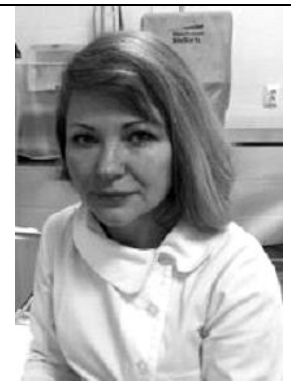

ORCID: 0000-0002-7913-7047

\section{Ph.D. Yuliia Yakusheva}

e-mail: yakusheva@vnmu.edu.ua

Candidate of Biological Sciences, Senior Lecturer. Department of Physical Education and Therapeutic Physical training of National Pirogov Memoria Medical University

Scientific direction - features of the indicators of central hemodynamics, depending on the parameters of the body structure of athletes

ORCID ID: 0000-0002-4811-8089
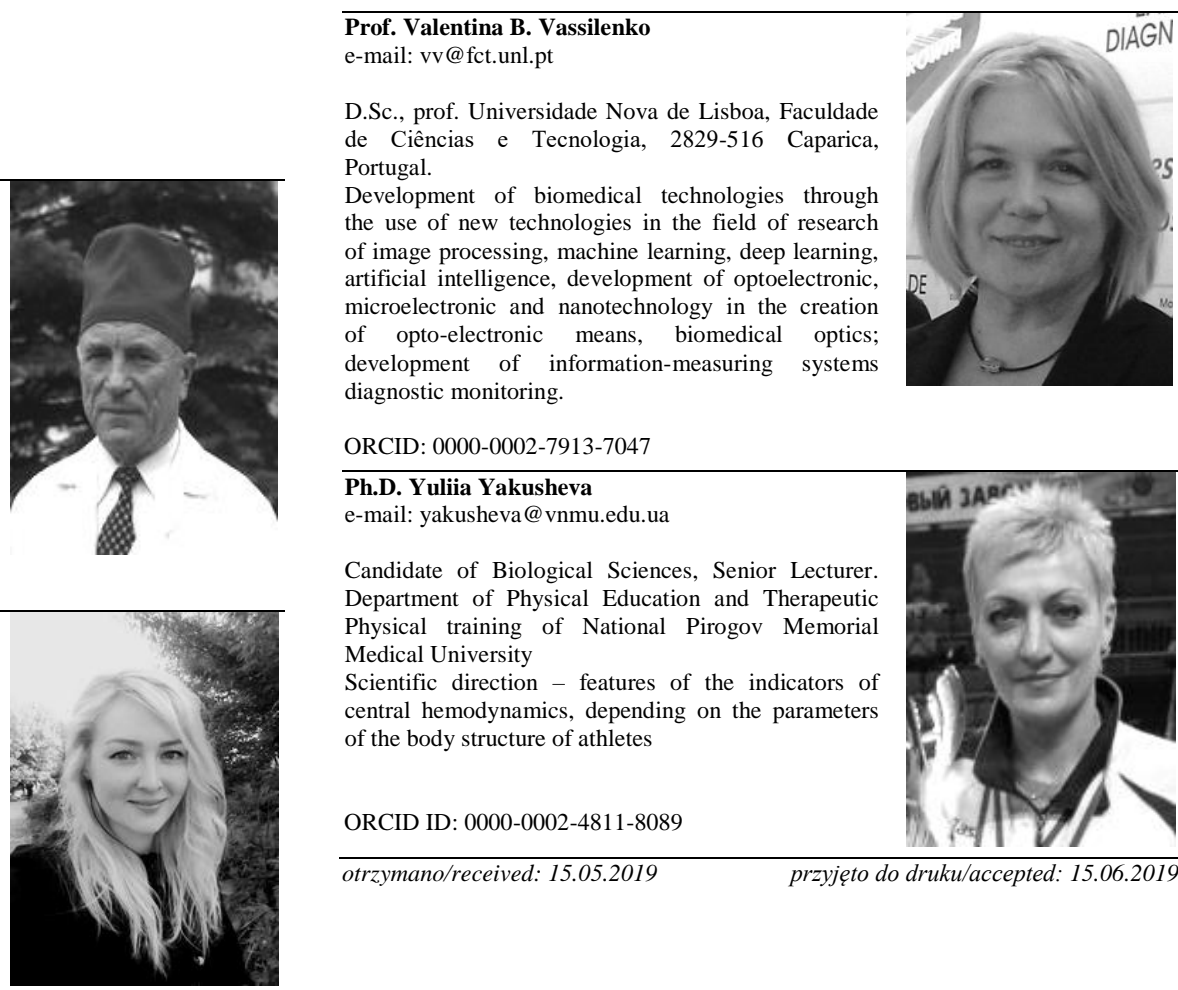

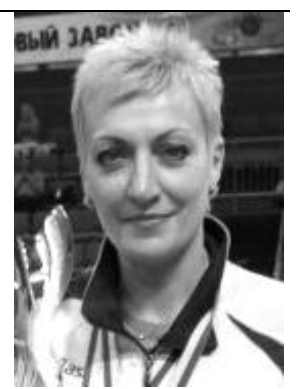

przyjęto do druku/accepted: 15.06 .2019 